\title{
Pancreas transplantation: review
}

\author{
Transplante de pâncreas: revisão \\ Roberto Ferreira Meirelles Júnior ${ }^{1}$, Paolo Salvalaggio ${ }^{1}$, Alvaro Pacheco-Silva ${ }^{1,2}$
}

\begin{abstract}
Vascularized pancreas transplantation is the only treatment that establishes normal glucose levels and normalizes glycosylated hemoglobin levels in type 1 diabetic patients. The first vascularized pancreas transplant was performed by William Kelly and Richard Lillehei, to treat a type 1 diabetes patient, in December 1966. In Brazil, Edison Teixeira performed the first isolated segmental pancreas transplant in 1968. Until the 1980s, pancreas transplants were restricted to a few centers of the United States and Europe. The introduction of tacrolimus and mycophenolate mofetil in 1994, led to a significant outcome improvement and consequently, an increase in pancreas transplants in several countries. According to the International Pancreas Transplant Registry, until December 31st, 2010, more than 35 thousand pancreas transplants had been performed. The one-year survival of patients and pancreatic grafts exceeds 95 and $83 \%$, respectively. The better survival of pancreatic $(86 \%)$ and renal $(93 \%)$ grafts in the first year after transplantation is in the simultaneous pancreas-kidney transplant group of patients. Immunological loss in the first year after transplant for simultaneous pancreas-kidney, pancreas after kidney, and pancreas alone are $1.8,3.7$, and $6 \%$, respectively. Pancreas transplant has 10 to $20 \%$ surgical complications requiring laparotomy. Besides enhancing quality of life, pancreatic transplant increases survival of uremic diabetic patient as compared to uremic diabetic patients on dialysis or with kidney transplantation alone.
\end{abstract}

Keywords: Pancreas transplantation; Diabetes mellitus; Immunosuppression; Renal insufficiency

\section{RESUMO}

0 transplante vascularizado de pâncreas é o único tratamento que estabelece normoglicemia e normaliza os níveis séricos de hemoglobina glicosilada em pacientes diabéticos tipo 1.0 primeiro transplante de pâncreas vascularizado foi realizado para tratar um paciente diabético tipo 1 em dezembro de 1966, por William Kelly e Richard Lillehei. No Brasil, Edison Teixeira realizou 0 primeiro transplante de pâncreas segmentar isolado em 1968. Até a década de 1980, os transplantes de pâncreas ficaram restritos a poucos centros dos Estados Unidos e da
Europa. A introdução dos imunossupressores tacrolimo e micofenolato mofetila, a partir de 1994, propiciou a melhora significativa dos resultados e a consequente realização de transplantes em escala crescente em vários países. Segundo o Registro Internacional de Transplante de Pâncreas, foram realizados, até 31 de dezembro de 2010, mais de 35 mil transplantes de pâncreas. Sobrevida no primeiro ano dos pacientes e dos enxertos pancreáticos excede, respectivamente, 95 e $83 \%$. A melhor sobrevida dos enxertos pancreático (86\%) e renal (93\%), no primeiro ano pós-transplante, está na categoria de transplante simultâneo de pâncreas e rim. As perdas imunológicas no primeiro ano pós-transplante para transplante simultâneo de pâncreas e rim, transplante de pâncreas após rim e transplante de pâncreas isolado foram, respectivamente, 1,8, 3,7, e 6\%. 0 transplante de pâncreas apresenta de 10 a $20 \%$ de complicações cirúrgicas, necessitando laparotomia. 0 transplante de pâncreas, além de melhorar a qualidade de vida, proporciona o aumento da sobrevida em diabéticos urêmicos, comparados aos diabéticos em diálise ou transplantados renais.

Descritores: Transplante de pâncreas; Diabetes mellitus; Imunossupressão; Insuficiência renal

\section{INTRODUCTION}

Vascularized pancreas transplantation is the only treatment that establishes normal glucose levels and normalizes serum levels of glycosylated hemoglobin in type 1 diabetes patients. ${ }^{(1,2)}$ Pancreatic islet cell transplantation is an alternative treatment for type 1 diabetes. ${ }^{(3)}$ Evolution of pancreatic transplant as treatment of type 1 diabetes was determined by the advancement of technology as to surgical technique, preservation of organs, and immunosuppression. $^{(4,5)}$

\section{BACKGROUND}

The first vascularized pancreas transplant was performed simultaneously with a renal graft to treat a type 1 diabetes

${ }^{1}$ Hospital Israelita Albert Einstein, São Paulo, SP, Brazil.

Corresponding author: Roberto Ferreira Meirelles Júnior - Avenida Albert Einstein, 627/701, building A1, room 112 - Morumbi - Zip code: $05652-900$ - São Paulo, SP, Brazil - Phone: (55 11) 2151-9222 E-mail: roberto.meirelles@einstein.br

Received on: May 5, 2014 - Accepted on: Feb 8, 2015

DOI: 10.1590/\$1679-45082015RW3163 
patient with uremia. It took place in December 1966, at the Hospital of the University of Minnesota, in the United States, and was conducted by William Kelly and Richard Lillehei. ${ }^{(6)}$ In Brazil, Edison Teixeira et al. conducted the first isolated segmental pancreas transplant in 1968, in Rio de Janeiro. ${ }^{(7)}$

In 1974, the first clinical transplant of Langerhans islet cells was performed at the University of Minnesota. ${ }^{(8)}$ In 1979, in order to overcome the immunological problems, David Sutherland carried out the first segmental pancreatic transplant with a living donor. ${ }^{(9)}$

Up until the 1980s, pancreatic transplantation was restricted to a few centers of the United States and Europe. The introduction of the immunosuppressants tacrolimus and mycophenolate mofetil, as of 1994, the evolution of surgical techniques and the routine use of a preserving solution at the University of Wisconsin, culminated with a significant improvement of the results and with the consequent increasing number of transplants performed in several countries. ${ }^{(10)}$

In Brazil, pancreas transplantation grew by the end of the 1990s, when the National Unified Healthcare System (SUS, Sistema Único de Saúde) authorized the procedure.

The main objectives of pancreatic transplants are better quality of life in type 1 diabetes patients, promoting independence from exogenous insulin and prevention of secondary complications of this type of diabetes (retinopathy, neuropathy, nephropathy, and vascular disease, besides protecting the transplanted kidney from developing diabetic nephropathy). ${ }^{(11)}$

\section{MODALITIES OF PANCREATIC TRANSPLANT RECIPIENTS AND INDICATIONS}

The modalities of pancreatic transplant recipients are simultaneous pancreas- kidney transplant (SPK); pancreas after kidney transplant (PAK); and pancreatic transplant alone (PTA).

The nomenclature "isolated pancreas" includes the categories PAK and PTA. The SPKT category is the most frequently performed, followed by PAK and more rarely, PTA.

Indications for pancreatic transplant are: SPK, which is for type 1 diabetics with uremia (chronic renal failure in pre-dialysis or on dialysis with creatinine clearance $<20 \mathrm{~mL} / \mathrm{min}$ ); PAK is done in type 1 diabetics with a normal renal function; and PTA, for type 1 diabetics who are not uremic. According to the recommendation of the American Diabetes Association, it is indicated in cases of acute and severe metabolic complications (hypoglycemia, hyperglycemia, and ketoacidosis), which require medical care; emotional problems with exogenous insulin therapy, that are so serious to the point of being incapacitating; and of consistent failure to prevent acute complications with insulin-based treatment. Protocols intended to assure an objective multidisciplinary evaluation of the clinical conditions and the eligibility for PTA should be established and accompanied. ${ }^{(12)}$

\section{RECIPIENT SELECTION}

The criteria for selection of recipients are: type 1 diabetes patient; age range between 18 and 55 years; absence of generalized complications secondary to diabetes; nonrenal organ failure; absence of malignant disease or cure criterion; no contraindication to immunosuppression; emotional and social stability (to understand the risks and benefits of surgery and of the need for immunosuppression and of its side effects).

Exclusion criteria for recipients are: impaired cardiac function (recent acute myocardial infarction, angina with intractable coronary obstruction, and echocardiography with ejection fraction $<50 \%$ ); emotional and social instability (psychiatric disorder, alcohol or illicit-substance dependence, and lack of motivation); presence of active infection or sepsis (infection of the wall/peritonitis); presence of a malignant tumor; and obesity with body mass index $>30 \mathrm{~kg} / \mathrm{m}^{2}$.

These are relative exclusion criteria for recipients with findings of irreversible or severe disease (heart, lungs, and liver); positive serology for acquired immunodeficiency virus; positive crossmatching result (T cells); and type 2 diabetes.

\section{DONOR SELECTION}

The selection of deceased donors should be made the closest possible to the ideal donor in order to obtain better results. Thus, adequate maintenance of the potential brain death donor is fundamental to avoid primarily hemodynamic instability. In addition to blood compatibility in the $\mathrm{ABO}$ system and a negative crossmatching, the age range for pancreas donor has been considered between 5 and 50 years. The weight of the donor should be between 30 and $50 \mathrm{~kg}$ if there is retrieval of the pancreas without the liver, and $>50 \mathrm{~kg}$ if both pancreas and liver are procured. ${ }^{(13)}$

Macroscopic evaluation of the pancreas considers the presence of signs of acute pancreatitis, glandular edema, hematoma, fatty infiltration and/or hardened 
consistency, since such factors increase the risk of posttransplant complications, and under these conditions, the grafts should be discarded.

Other conditions that might determine the exclusion of donors are type 1 diabetes; pancreatic disease; prior surgery of the duodenum, pancreas, or splenectomy; malignant tumor; positive serology for infectious diseases (acquired immunodeficiency syndrome, hepatitis B and C), chronic liver disease; morbid obesity with body mass index $>40 \mathrm{~kg} / \mathrm{m}^{2}$, and past history of chronic alcohol abuse.

\section{SURGICAL TECHNIQUE}

\section{Donor}

Procurement of the pancreatic graft is generally part of the removal of multiple intra-abdominal organs. The removal of a combined liver and pancreas graft requires a unique technique. ${ }^{(14)}$ After removal of the hepatic graft, the pancreatic graft is removed en bloc, along with the duodenum and spleen, preserving the vascular stumps of the superior mesenteric and splenic arteries, and of the portal vein. The pancreatic and vascular grafts should be immersed in $1 \mathrm{~L}$ of Belzer solution (Figure 1).

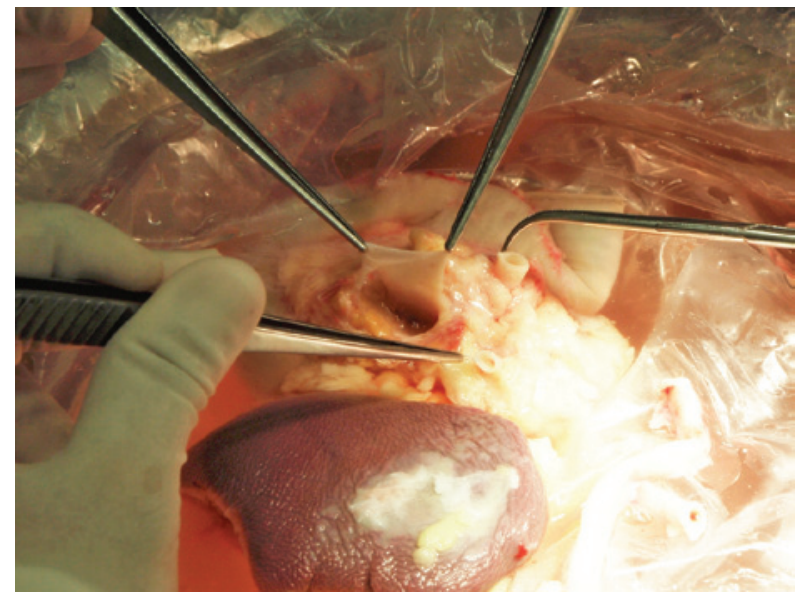

Figure 1. Aspect of the pancreatic graft after removal

\section{Graft}

On backtable surgery, the pancreatoduodenal graft is prepared basically by removing the spleen, shortening the duodenal segment, suture, and invagination of the duodenal borders, mobilization of the portal vein, and vascular Y graft reconstruction (iliac arteries from the donor with the pancreatic graft superior mesenteric artery and splenic artery) (Figure 2).

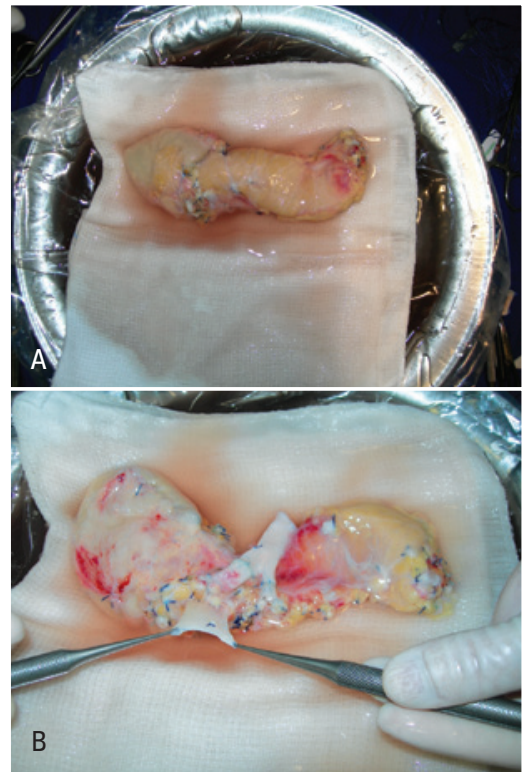

Figure 2. Anterior aspect of the pancreatic graft after splenectomy, reduction of the duodenum $(A)$, and posterior aspect of the pancreatic graft after performance of the arterial $Y$ graft $(B)$

\section{Recipient}

The preferential access route is midline laparotomy. The pancreatic implant is preferentially performed in the right iliac fossa of the recipient, since the right iliac vessels are more accessible. The implant of the pancreas can be done by drainage of systemic or portal venous blood. ${ }^{(15)}$ Drainage of pancreatic exocrine secretion of the graft can be enteric (side-to-side duodenojejunal anastomosis) or vesical (side-to-side duodenovesical anastomosis) (Figure 3).

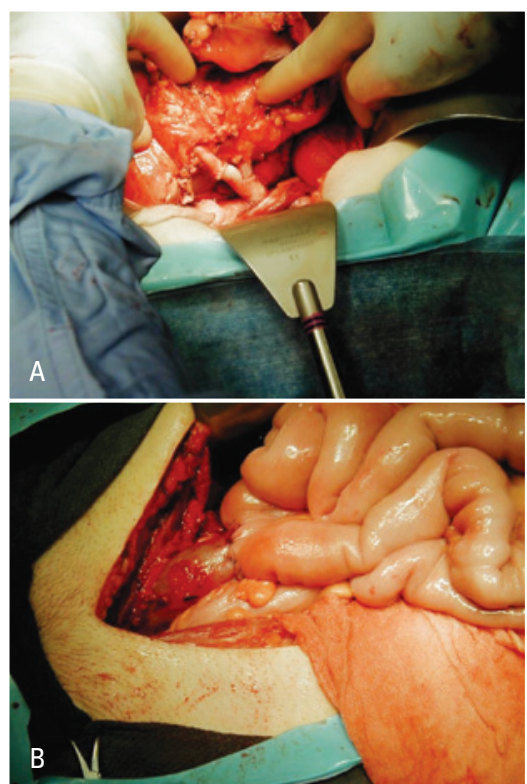

Figure 3. Immediate aspect of pancreatic graft revascularization (A) and enteric shunt $(B)$ 


\section{IMMUNOSUPPRESSION}

Today the immunosuppression regimens most frequently used include the use of induction and maintenance therapy. The medications used for induction are antilymphocyte serum, such as polyclonal anti-T-cell antibodies (ATG), or with monoclonal anti-interleukin-2 receptor (antiIL-2R) antibodies (basiliximab and daclizumab). Maintenance therapy is based on the use of a calcineurin inhibitor (tacrolimus) associated with an antimetabolite (mycophenolate mofetil) and corticoid (prednisone).

\section{SURVIVAL}

According to the International Pancreatic Transplant Registry, up to December 31st, 2010, more than 35 thousand pancreas transplants had been done; in that, 24 thousand in the United States and 12 thousand in other countries. The most frequently used modality of pancreatic transplant was SPK $(75 \%)$, followed by PAK $(12 \%)$, and PTA $(7 \%)$. The number of pancreatic transplants grew until 2004, and since then, it has gradually diminished. ${ }^{(16)}$ In the United States, survival of patients during the first and fifth years after a pancreatic transplant was, respectively, greater than 95 and $88 \%$. Survival of the pancreatic grafts exceed in the first and fifth years post-transplant, respectively, 84 and $60 \%$. The best survival of the pancreatic $(86 \%)$ and renal $(93 \%)$ grafts in the first post-transplant year is in the SPK category. Immunological loss in the first posttransplant year for SPK, PAK and PTA was, respectively, $1.8,3.7$, and $6 \% .^{(17,18)}$

\section{COMPLICATIONS}

In general, the primary complication related to pancreatic graft loss is technical failure, followed by acute or chronic rejection. Technical failure is understood as the loss of the graft in the first three months of transplant due to vascular thrombosis $(50 \%)$, pancreatitis $(20 \%)$, infection (18\%), fistulas (6.5\%), and hemorrhage (2.4\%). However, PAK and PTA recipients present with rejection as the main complication related to loss of the pancreatic graft. Other complications are infection and dehiscence of the abdominal wall. ${ }^{(19)}$

Pancreatic transplant presents 10 to $20 \%$ of surgical complications that requiring review laparotomy. The risk factors for surgical complications include prolonged time in peritoneal dialysis, donor or recipient with a body mass index $>28 \mathrm{~kg} / \mathrm{m}^{2}$, donor or recipient age over 45 years, cerebrovascular disease as cause of donor death, prolonged preservation time ( $>20$ hours), retransplantation, and prior abdominal surgery. ${ }^{(1,10,20-24)}$

Pancreatic transplants with vesical drainage imply frequent and severe urological and metabolic complications. Approximately 10 to $25 \%$ of patients submitted to pancreatic transplant with bladder drainage need to be submitted to intestinal conversion of the graft's exogenous drainage. ${ }^{(25)}$ The main metabolic complications are metabolic acidosis and dehydration due to loss of water and sodium bicarbonate in the urine. These patients should receive adequate fluid and bicarbonate replacement in the follow-up of pancreatic transplant with bladder drainage.

One of the most feared complications in pancreatic transplant with enteric drainage is intestinal leak, since it poses risks to patient's survival. The incidence of intestinal leak range from 5 to $8 \%$, and most occur during the immediate postoperative period. The early leak is related to technical problems, such as impaired blood irrigation and ischemia. The potential risk factors for the occurrence of early intestinal leak are prolonged cold ischemia time, duodenal trauma, postreperfusion pancreatitis, and intra-abdominal infection. Its treatment generally leads to the removal of the pancreatic graft. ${ }^{(26-29)}$

At the beginning of experience with pancreas transplant, it was noted that about $80 \%$ of the patients submitted to SPK presented with a clinical picture of acute rejection in the first year after transplant. Of these, $27 \%$ presented with isolated rejection of the pancreatic graft. Loss of the pancreatic graft by rejection reached up to $20 \%$ of the cases. The criteria used for the diagnosis of pancreatic graft rejection are increased serum creatinine levels (SPK), decreased amylasuria (bladder drainage), and high serum lipase levels. Pancreatic biopsy (ultrasound-guided puncture) is the gold standard for diagnosis of rejection. ${ }^{(30,31)}$

Despite better pancreatic transplant results, infectious complications continue to be the primary causes of morbidity and mortality. The most frequent etiology is bacterial infection, and the urinary tract and abdominal wall are the most affected sites. Patients submitted to pancreas transplant have a high risk of developing infection by cytomegalovirus due to the use of antilymphocyte serum in immunosuppression protocols. The mean incidence is $25 \%$.

Early diagnosis of the type of infection, especially fungal infection, is fundamental for treatment success. Administration of antibiotics, antifungal agents, and antiviral agents is recommended.

In a late phase, the major complications are related to the clinical picture of chronic rejection and infectious 
complications. Myocardial infarction and sudden death are significant causes of mortality.

\section{CONCLUSION}

Vascularized pancreas transplantation remains as the most effective treatment for type 1 diabetes. There are surgical complications and immunosuppression is mandatory. However, there is improved quality of life and greater survival in uremic diabetic patients after pancreas transplant. Isolated pancreatic transplant is the appropriate treatment for patients with labile diabetes and should be indicated, as per recommendations of the American Diabetes Association. The development of islet cell transplants should decrease surgical complications, and achieving tolerance might eliminate immunosuppression.

\section{REFERENCES}

1. Sutherland DE, Gruessner RW, Dunn DL, Matas AJ, Humar A, Kandaswamy R, et al. Lessons learned from more than 1,000 pancreas transplants at a single institution. Ann Surg. 2001;233(4):463-501. Review.

2. Mittal S, Gough SC. Pancreas transplantation: a treatment option for people with diabetes. Diabet Med. 2014;31(5):512-21. Review.

3. Pepper AR, Gala-Lopez B, Ziff 0, Shapiro AJ. Current status of clinical islet transplantation. World J Transplant. 2013;3(4):48-53.

4. Kandaswamy R, Stock PG, Skeans MA, Gustafson SK, Sleeman EF, Wainright JL, et al. OPTN/SRTR 2011 Annual Data Report: pancreas. Am J Transplant. 2013;13 Suppl 1:47-72.

5. McLaren AJ, Friend PJ. Trends in organ preservation. Transpl Int. 2003; 16(10):701-8. Review.

6. Kelly WD, Lillehei RC, Merkel FK, Idezuki Y, Goetz FC. Allotransplantation of the pancreas and duodenum along with the kidney in diabetic nephropathy. Surgery. 1967;61(6):827-37.

7. Teixeira E, Monteiro G, De Cenzo M, Teixeira A, Bergan JJ. Transplantation of the isolated pancreas: report on the first human case. Bull Soc Int Chir. 1970;29(6):337-44.

8. Sutherland DE, Matas AJ, Najarian JS. Pancreatic islet cell transplantation. Surg Clin North Am. 1978;58(2):365-82.

9. Sutherland DE, Goetz FC, Najarian JS. Living-related donor segmental pancreatectomy for transplantation. Transplant Proc. 1980;12(4 Suppl 2):19-25.

10. Gruessner AC, Sutherland DE. Pancreas transplant outcomes for United States (US) and non-US cases as reported to the United Network for Organ Sharing (UNOS) and the International Pancreas Transplant Registry (IPTR) as of June 2004. Clin Transplant. 2005;19(4):433-55. Review.

11. Mauer M, Fioretto P. Pancreas transplantation and reversal of diabetic nephropathy lesions. Med Clin North Am. 2013;97(1):109-14.

12. Robertson P, Davis C, Larsen J, Stratta R, Sutherland DE; American Diabetes Association. Pancreas transplantation in type 1 diabetes. Diabetes Care. 2004; 27 Suppl 1:S105.

13. Krieger NR, Odorico JS, Heisey DM, D’Alessandro AM, Knechtle SJ, Pirsch
JD, et al. Underutilization of pancreas donors. Transplantation. 2003;75(8): 1271-6.

14. Marsh CL, Perkins JD, Sutherland DE, Corry RJ, Sterioff S. Combined hepatic and pancreaticoduodenal procurement for transplantation. Surg Gynecol Obstet. 1989;168(3):254-8.

15. Rogers J, Farney AC, Orlando G, Farooq U, Al-Shraideh Y, Stratta RJ. Pancreas transplantation with portal venous drainage with an emphasis on technical aspects. Clin Transplant. 2014;28(1):16-26. Review.

16. Israni AK, Skeans MA, Gustafson SK, Schnitzler MA, Wainright JL, Carrico RJ, et al. OPTN/SRTR 2012 Annual Data Report: pancreas. Am J Transplant. 2014;14 Suppl 1:45-68.

17. Gruessner AC. 2011 update on pancreas transplantation: comprehensive trend analysis of 25,000 cases followed up over the course of twenty-four years at the International Pancreas Transplant Registry (IPTR). Rev Diabet Stud. 2011; 8(1):6-16. Review.

18. Gruessner RW, Gruessner AC. The current state of pancreas transplantation. Nat Rev Endocrinol. 2013;9(9):555-62. Review.

19. Humar A, Ramcharan T, Kandaswamy R, Gruessner RW, Gruessner AC Sutherland DE. Technical failures after pancreas transplants: why grafts fail and the risk factors--a multivariate analysis. Transplantation. 2004;78(8): 1188-92.

20. Stratta RJ, Taylor RJ, Gill IS. Pancreas transplantation: a managed cure approach to diabetes. Curr Probl Surg. 1996;33(9):709-808. Review.

21. Humar A, Kandaswamy R, Granger D, Gruessner RW, Gruessner AC, Sutherland $D E$. Decreased surgical risks of pancreas transplantation in the modern era. Ann Surg. 2000;231(2):269-75.

22. Troppmann C, Gruessner AC, Dunn DL, Sutherland DE, Gruessner RW. Surgical complications requiring early relaparotomy after pancreas transplantation: a multivariate risk factor and economic impact analysis of the cyclosporine era. Ann Surg. 1998;227(2):255-68.

23. Humar A, Kandaswamy R, Drangstveit MB, Parr E, Gruessner AG, Sutherland $D E$. Prolonged preservation increases surgical complications after pancreas transplants. Surgery. 2000;127(5):545-51.

24. Humar A, Ramcharan T, Kandaswamy R, Gruessner RW, Gruessner AG, Sutherland DE. The impact of donor obesity on outcomes after cadaver pancreas transplants. Am J Transplant. 2004;4(4):605-10.

25. Stratta RJ. Surgical nuances in pancreas transplantation. Transplant Proc. 2005;37(2):1291-3. Review.

26. Sansalone CV, Maione G, Aseni P, Mangoni I, De Roberto A, Soldano S, et al. Surgical complications are the main cause of pancreatic allograft loss in pancreas-kidney transplant recipients. Transplant Proc. 2005;37(6):2651-3.

27. Hanish SI, Petersen RP, Collins BH, Tuttle-Newhall J, Marroquin CE, Kuo PC, et al. Obesity predicts increased overall complications following pancreas transplantation. Transplant Proc. 2005;37(8):3564-6.

28. Nath DS, Gruessner A, Kandaswamy R, Gruessner RW, Sutherland DE, Humar A. Late anastomotic leaks in pancreas transplant recipients - clinical characteristics and predisposing factors. Clin Transplant. 2005;19(2):220-4.

29. Corry RJ, Chakrabarti P, Shapiro R, Jordan ML, Scantlebury VP, Vivas CA. Comparison of enteric versus bladder drainage in pancreas transplantation. Transplant Proc. 2001;33(1-2):1647-51.

30. de Kort H, Roufosse C, Bajema IM, Drachenberg CB. Pancreas transplantation, antibodies and rejection: where do we stand? Curr Opin Organ Transplant. 2013;18(3):337-44. Review.

31. Dong M, Parsaik AK, Kremers W, Sun A, Dean P, Prieto M, et al. Acute pancreas allograft rejection is associated with increased risk of graft failure in pancreas transplantation. Am J Transplant. 2013;13(4):1019-25. 